Proceedings

\title{
Decomposability and un-Coordination between Flower and Leaf Litter ${ }^{\dagger}$
}

\author{
Mery Alencar*, Ana Asato, Adriano Caliman \\ * Correspondence: merypynck@hotmail.com \\ + Presented at the 1st International Electronic Conference on Biological Diversity, Ecology and Evolution, \\ 15-31 March 2021; Available online: https://bdee2021.sciforum.net/.
}

Abstract: Organs and nutrient allocation are linking the evolved strategies of plant species with their variations affecting the effects on ecosystems process. The differences in litter quality are important factors shaping the decomposition rate, although the works are centered only on leaf litter quality. We aimed to analyze the trait coordination and phylogenetic signal in leaf and flower litter for 29 species. We evaluated the decomposition rate for each litter type in a common garden approach. Also, we measured 13 functional traits, included physical and chemical. And we estimated phylogenetic signal in litter decomposition rates for each litter type using Blomberg's K. Flower litter had higher rates of decomposition, exhibited $11.81 \%$ mean remaining mass, while the leaf litter had $40 \%$. The measured traits reflected a gradient from a conservative to acquisitive, but their prediction was dependent on each litter type. Despite this, we found the un-coordination among flower and leaf litter and the absence of phylogenetic signal. In this work, we were able to show that floral and leaf litter are uncoordinated and poorly correlated. Despite the lack of phylogenetic signal, we show that leaf litter is not a good predictor for the plant as a whole, so to better understand decomposition we need to take into account other compartments of variation, such as within-individual.

Keywords: within-individual variation; ecosystem process; evolutionary ecology; litter decomposition

Citation: Mery Alencar *, Ana Asato, Adriano Caliman. Decomposability and un-coordination between flower and leaf litter. Proceedings 2021, 68, x.

https://doi.org/10.3390/xxxxx

Publisher's Note: MDPI stays neutral with regard to jurisdictional claims in published maps and institutional affiliations.

Copyright: (c) 2021 by the authors. Submitted for possible open access publication under the terms and conditions of the Creative Commons Attribution (CC BY) license (http://creativecommons.org/licenses /by/4.0/). 